\title{
Murine sperm capacitation, oocyte penetration and decondensation following moderate alcohol intake
}

\author{
Melisa C Sánchez ${ }^{1}$, Vanina A Fontana ${ }^{1,2}$, Camila Galotto ${ }^{1}$, Maite Y Cambiasso ${ }^{1}$, \\ Cristian M A Sobarzo ${ }^{3}$, Lucrecia Calvo1, Juan C Calvo ${ }^{1,2}$ and Elisa Cebral ${ }^{4,5}$ \\ ${ }^{1}$ CONICET, Instituto de Biología y Medicina Experimental (IByME), Buenos Aires, Argentina, ${ }^{2}$ Departamento de \\ Química Biológica, Facultad de Ciencias Exactas y Naturales (FCEyN), Universidad de Buenos Aires (UBA), Buenos \\ Aires, Argentina, ${ }^{3}$ Universidad de Buenos Aires, Facultad de Medicina, CONICET-Universidad de Buenos Aires, \\ Instituto de Investigaciones Biomédicas (INBIOMED), Buenos Aires, Argentina, ${ }^{4}$ Universidad de Buenos Aires, \\ Facultad de Ciencias Exactas y Naturales, Buenos Aires, Argentina and ${ }^{5}$ CONICET-Universidad de Buenos Aires, \\ Instituto de Biodiversidad y Biología Experimental y Aplicada (IBBEA-CONICET), Buenos Aires, Argentina
}

Correspondence should be addressed to E Cebral; Email: ecebral@hotmail.com

\begin{abstract}
Male chronic alcohol abuse causes testicular failure and infertility. We analyzed the effects of moderate sub-chronic alcohol intake on sperm morphology, capacitation, fertilization and sperm head decondensation. CF-1 male mice were administered $15 \%$ ethanol in drinking water for 15 days; control mice received ethanol-free water. Similar patterns of tyrosine phosphorylation were observed in capacitated spermatozoa of control and treated males. Percentage of hyperactivation $(\mathrm{H})$ and spontaneous (SAR) and progesteroneinduced (IAR) acrosome reaction significantly decreased at 120 and $\mathbf{1 5 0} \mathrm{min}$ of capacitation in treated males compared to controls (H: $14.1 \pm 2.5$ vs $23.7 \pm 2.6, P<0.05 ;$ SAR-T120 min: $17.9 \pm 2.5$ vs $32.9 \pm 4.1, P<0.01 ;$ IAR-150 min: $43.3 \pm 3.5$ vs $73.1 \pm 1.1$, $P<0.001, n=6)$. During in vitro fertilization (2.5, 3.5 and $4.5 \mathrm{~h}$ post-insemination), there was an increased percentage of fertilized oocytes (with a decondensed sperm head and one or two pronuclei) in treated males $(P<0.001, n=7)$. After 60 min of in vitro decondensation with glutathione plus heparin, the percentage of decondensed sperm heads was significantly higher in treated males than in controls (mean \pm S.D.: $57.1 \pm 5.6$ vs $48.3 \pm 4.5, P<0.05, n=5$ ). The percentage of morphologically normal sperm heads was significantly decreased in treated males with respect to controls $(P<0.001, n=9)$. These results show that short-term moderate alcohol consumption in outbred mice affect sperm morphology, hyperactivation, acrosomal exocytosis, and the dynamics of in vitro fertilization and in vitro sperm nuclear decondensation.

Reproduction (2018) 155 529-541
\end{abstract}

\section{Introduction}

It is widely known that alcohol abuse produces a variety of medical, psycho-sociological and physiological disorders at different levels, including the reproductive system (Canteros et al. 1995, Cebral et al. 1997, 1998a,b, 2011, Lee et al. 2010). Numerous studies have shown the deleterious effects of chronic heavy alcohol consumption on testicular function and spermatogenesis (Shayakhmetova et al. 2013, 2014), on testosterone serum levels (Salonen et al. 1992, Muthusami \& Chinnaswamy 2005, Lee et al. 2010, Jensen et al. 2014, Sliwowska et al. 2016) and on hypothalamic-pituitary-testicular axis function (Cicero \& Badger 1977, Dees et al. 1990, Välimäki et al. 1990, Salonen et al. 1992, Zhang et al. 2005). Clinical manifestations in alcoholic men include hypogonadism, testicular atrophy, feminization, sexual dysfunction (Van Thiel et al. 1990, Van Heertum \& Rossi 2017), infertility and delayed sexual maturation
(Anderson et al. 1989). Many studies have suggested that one of the most important negative effects of chronic alcohol ingestion occur in sperm parameters (Rahimipour et al. 2013, Condorelli et al. 2015).

Reproductive function in the ethanol-disrupted male depends on alcohol concentration and duration of ethanol exposure, issues that remain controversial. A decrease in the quality of semen parameters has been consistently documented in heavy consumers of alcohol (Martini et al. 2004, Muthusami \& Chinnaswamy 2005, Gaur et al. 2010, Hansen et al. 2012). On the other hand, the effects of low to moderate consumption of alcohol do not appear to be clinically significant. Several studies have shown no effect in semen parameters with moderate alcohol consumption (Stutz et al. 2004, Van Heertum \& Rossi 2017). de Jong et al. (2014) failed to show a significant relationship between alcohol consumption and not only sperm parameters but also pregnancy outcome. Others have observed a 
positive effect of male alcohol intake on fertilization rate (Firns et al. 2015). Regarding duration of alcohol exposure, multiple studies have showed altered sperm morphology with regular alcohol drinking, correlating with low fecundity (Van Heertum \& Rossi 2017). Chronic consumption of $5 \%$ ethanol for 20 weeks or $6 \%$ ethanol for 5 weeks (that produced $45 \%$ ethanolderived calories (EDC)) led to low caudal sperm content in rats (Anderson et al. 1983, Willis et al. 1983). Consumption of $5 \%$ ethanol for 6 weeks induced increased percentage of morphologically abnormal spermatozoa (Abel \& Moore 1987). Most of the studies that have analyzed the effects of alcohol intake on testicular and sperm parameters have used chronic alcohol intake paradigms and alterations in murine male fertilizing ability following short-term moderate ethanol consumption remain unclear. We have previously shown that chronic ingestion of $5 \%$ alcohol (in drinking water) for 30 days by hybrid $(\mathrm{C} 57 / \mathrm{BI} \times \mathrm{CBA}) \mathrm{F} 1$ adult male mice did not affect in vitro fertilization (IVF; Cebral et al. 1997). Considering that the CF-1 outbred mouse has a high genetic polymorphism and variability in terms of biological responses, this mouse colony could provide a feasible model to identify effects on sperm function and fertility that resemble those observed in alcoholic men who consume alcohol in a sub-chronic and moderate manner.

The cellular mechanisms underlying the morphological and physiological changes in spermatozoa and fertility following male alcohol ingestion have been little studied. Alcohol consumption may affect, directly or indirectly, spermatogenesis, differentiation/elongation of spermatids, compaction of sperm chromatin and sperm epididymal maturation, and thus, negatively alter capacitation, hyperactivation and acrosome reaction and ulterior events of fertilization. Both acute and chronic alcohol consumption have been shown to affect sperm chromatin/DNA integrity and apoptosis (Talebi et al. 2011, Rahimipour et al. 2013), and result in the production of sperm with a less compacted chromatin, suggesting that these alterations could be one of the possible causes of infertility due to alcohol consumption.

Considering the lack of information regarding the effect of sub-chronic alcohol ingestion on the sperm fertility, the aim of this paper was to analyze its effect on sperm capacitation and associated functional parameters, on the dynamics of oocyte penetration and sperm head decondensation, and on its potential relationship with altered sperm morphology, in an outbred adult mouse model. Our hypothesis is that moderate alcohol intake for a short period of time negatively affects sperm hyperactivation and acrosome exocytosis and that the kinetics of in vitro oocyte fertilization is altered by changes in time course of sperm head decondensation.

\section{Materials and methods}

\section{Animals}

Outbred CF-1 sexually mature mice (Mus musculus, CrlFcen:CF1, Mouse Genome Informatic (MGI)), produced by FCEN (School of Exact and Natural Sciences) of the University of Buenos Aires (Buenos Aires, Argentina) were housed by sex in groups of three to four mice per cage. They were kept in controlled room temperature $\left(22^{\circ} \mathrm{C}\right)$ and light cycle (14 h light/10 h dark) and were fed commercial mouse chow (Alimento 'Balanceado Cooperación Rata-Ratón' from the Asociación Cooperativa de Alimentos S.A. Buenos Aires, Argentina) and tap water ad libitum. At the outset of ethanol treatment, CF-1 male and female mice were 60 days old, with average body weight between 27 and $30 \mathrm{~g}$.

\section{Ethanol treatment and assessment of ethanol intake and blood alcohol concentration}

These experiments were carried out in accordance to regulations and ethical standards of Institutional Animal Care and Use Committee (IACUC, protocol Nr 57), from Facultad de Ciencias Exactas y Naturales, Universidad de Buenos Aires (FCEN-UBA Argentina), and in accordance with the guidelines of the National Institutes of Health (NIH).

Adult male mice were given access to $15 \%(\mathrm{v} / \mathrm{v})$ ethanol in drinking water for 15 days (treated males) ad libitum. In a previous study, conditions for short-term moderate alcohol ingestion in the male were established by determining the ethanol concentration producing an adverse effect on morphology and functionality of epididymal spermatozoa. 5,10 or $15 \%$ ethanol was administered in drinking water for 15 days to CF-1 adult mouse. The concentration showing deleterious effects on sperm morphology and testes was $15 \%$ (data not shown). Control males received ethanol-free drinking water ad libitum. To monitor potential ethanol-related nutritional effects on body weight of treated mice, a group of animals were pair-fed for 15 days with standard commercial food and the same daily percentage of ethanol-derived calories (\% EDC) in drinking water as in treated animals. Water-control and pair-fed control mice consumed the same amount of liquid and food during the 15 days of the experiment, and no changes in body weight were detected between both groups at the end of treatment. Thus, water-control was chosen as the control group for subsequent experiments.

Control and treated males were weighed at the beginning and at the end of ethanol treatment. Every morning, the drinking volume and the quantity of food consumed were recorded to monitor the amounts of daily liquid, food, calorie intake (estimated by caloric value of the diet used (3976 kcal/ $\mathrm{kg}$ ) and EDC, estimated as $7.1 \mathrm{kcal} / \mathrm{g}$ ). From these data, the mean calorie intake and the percentage of EDC were estimated for each experimental group. At least 5 mice per experimental group were used in each experiment. On the morning of day 15 of ethanol administration, CF-1 males were killed by cervical dislocation and trunk blood was collected into heparinized Eppendorf tubes. Blood samples were held at $4^{\circ} \mathrm{C}$ for ethanol measurement using a commercial kit 
(NAD/NADH enzymatic assay, sensitivity $50.1 \mathrm{mg} / \mathrm{dL}$ ), within $4 \mathrm{~h}$ of collection. Blood alcohol concentration (BAC) was expressed as milligrams per deciliter.

\section{Epididymal sperm preparation}

Male mice were killed by cervical dislocation on the morning of day 15 of ethanol treatment. The epididymides of each male were dissected and both caudae were removed and transferred into a dish containing $400 \mu \mathrm{L}$ of In Vitro Fertilization Medium (IVFM: $99.3 \mathrm{mmol} / \mathrm{L} \quad \mathrm{NaCl}, 2.70 \mathrm{mmol} / \mathrm{L} \mathrm{KCl}$, $0.50 \mathrm{mmol} / \mathrm{L} \mathrm{MgSO}_{4} \cdot 6 \mathrm{H}_{2} \mathrm{O}, 1 \mathrm{mg} / \mathrm{mL}$ glucose, $0.31 \mathrm{mmol} / \mathrm{L}$ $\mathrm{Na}_{2} \mathrm{HPO}_{4} \cdot 2 \mathrm{H}_{2} \mathrm{O}, 1.80 \mathrm{mmol} / \mathrm{L} \mathrm{CaCl}_{2} . \mathrm{H}_{2} \mathrm{O}$ ) (Fraser \& Drury 1975), without bovine serum albumin (BSA). $\mathrm{pH}$ of the medium was adjusted to 7.3 with $25.07 \mathrm{mmol} / \mathrm{L} \mathrm{NaOH}$, and $0.0055 \mathrm{mg}$ sodium pyruvate and $0.35 \mathrm{~mL}$ L-Na-lactate $(60 \%$ syrup) were added to a final volume of $100 \mathrm{~mL}$. Spermatozoa were obtained by making small incisions in caudae tissue and allowing the dense mass of spermatozoa to disperse for $5 \mathrm{~min}$ at $37^{\circ} \mathrm{C}$. Tissue fragments were removed; the sperm suspension was homogenized, an aliquot of spermatozoa was collected to analyze sperm count and morphology, and spermatozoa were then incubated in capacitating conditions (supplemented with $3 \mathrm{mg} / \mathrm{mL}$ of BSA, Sigma Chemical), for $120 \mathrm{~min}$ at a final concentration of $2 \times 10^{6}$ spermatozoa $/ \mathrm{mL}$, according to Visconti et al. (1995). Another aliquot $\left(2 \times 10^{6}\right.$ spermatozoa) was kept in non-capacitating conditions (without BSA).

\section{Protein extraction and immunodetection of phosphotyrosine residues after capacitation}

After capacitation, sperm suspensions from 5 control and 5 treated males were centrifuged at $2800 \mathrm{~g}$ for $1 \mathrm{~min}$. Supernatants were discarded and pellets washed once with $1 \mathrm{~mL} \mathrm{PBS}$, for $2 \mathrm{~min}$ at $5000 \mathrm{rpm}$ at $37^{\circ} \mathrm{C}$. Supernatants were discarded leaving the cells in about $20 \mu \mathrm{L}$. Following addition of enough $6 \times$ Laemmli's loading buffer, containing $5 \% \beta$-mercaptoethanol and Bromophenol blue, samples were heated at $100^{\circ} \mathrm{C}$, for $5 \mathrm{~min}$ and centrifuged at 11,200 $\mathrm{g}$ for $5 \mathrm{~min}$. Supernatants were kept at $-20^{\circ} \mathrm{C}$ until further processed.

Sperm extracts, equivalent to $2 \times 10^{6}$ cells, were analyzed in $10 \%$ SDS-PAGE, with a $4 \%$ stacking gel, according to Laemmli (1970), at a constant current of $25 \mathrm{~mA}$ per gel, at room temperature. Molecular weight markers were loaded in one of the lanes.

Following electrophoresis, proteins were transferred onto a PVDF membrane, according to the method of Towbin et al. (1979), at a constant voltage of $110 \mathrm{~V}$, for $1 \mathrm{~h}$ at $4^{\circ} \mathrm{C}$. Transfer efficiency was checked by Ponceau Red staining. Phosphotyrosine containing bands were detected using an anti-phosphotyrosine antibody (Upstate Biotechnology Incorporated, NY, EEUU, Cat \# 05-321). Following incubation in blocking solution (0.1\% BSA, 0.4\% Tween-20, $1 \mathrm{mM}$ EDTA in TBS), for $1 \mathrm{~h}$, the membrane was incubated in monoclonal anti-phosphotyrosine antibody at a 1:1000 dilution in blocking solution, for $1 \mathrm{~h}$, at room temperature. After 4 washes, $5 \mathrm{~min}$ each, with PBS-0.1\% Tween-20, the membrane was incubated with second antibody (peroxidase-labeled rabbit mouse anti IgG, in a 1:5000 dilution), for $1 \mathrm{~h}$, at room temperature, in blocking solution. The membrane was finally washed as previously described and reactive bands were detected using an ECL kit (Amersham Life Science).

\section{Sperm morphology determination}

To evaluate sperm head and flagellum morphology, $10 \mu \mathrm{L}$ of caudal sperm suspension was placed on a slide. Immediately after drying, slides were fixed for $15 \mathrm{~min}$ in $5 \%$ formaldehyde in phosphate buffer (v/v), washed in distilled water and stained with the Spermac staining procedure (Spermac Stain Enterprises, Onderstepoort, South Africa), according to the manufacturer's instructions. Slides were examined at $\times 100$ under an Axiophot Zeiss microscope (Carl Zeiss) equipped with a camera driven by Olympus DP71 using an image analyzer Olympus cell Sens software (Olympus). Head morphology, acrosomal and post-acrosomal regions, cytoplasmic droplet, midpiece and flagellum were examined. The criteria for abnormal sperm morphology used were as follows: (1) abnormal head: increased or decreased size, flat head, partial or completely abnormal shape (round, small, large, double head), and/or abnormal acrosome (acrosome more than 30\% smaller or $70 \%$ larger than sperm head); (2) neck and midpiece defects: debris around the neck, thickened neck, midpiece measuring more than $30 \%$ of spermatozoa; (3) abnormal flagellum: double, coiled or broken flagellum, incorrect insertion of flagellum, presence of a cytoplasmic droplet. The mean percentage \pm S.D. (over a total 1000 spermatozoa evaluated/mouse) of abnormal sperm heads, neck-midpieces and flagella was calculated for 9 control and 9 treated males (Cebral et al. 2011).

\section{Sperm motility and hyperactivation assessment}

Sperm motility and hyperactivation were evaluated at 0 , 60 and 120 min of in vitro capacitation. Immotile, motile and hyperactivated spermatozoa were determined using a Neubauer chamber. Motility was expressed as the mean percentage of motile spermatozoa/total number of spermatozoa, and hyperactivation was expressed as the mean percentage of hyperactivated spermatozoa over the total number of motile spermatozoa \pm standard error of the mean (S.E.M.). 6 males were evaluated in each group.

\section{Acrosomal reaction analysis}

The HOS-Spermac assay allows simultaneous detection of acrosome-reacted spermatozoa and motile spermatozoa. Briefly, different aliquots of sperm suspension were collected every $60 \mathrm{~min}$ from time zero $(t=0)$ up to $120 \mathrm{~min}$ of capacitation (time course of spontaneous acrosomal reaction). At $120 \mathrm{~min}$, $15 \mu \mathrm{M}$ progesterone (final concentration) (Sigma Chemical Company) was added to the sperm suspension and incubated for an additional $30 \mathrm{~min}$ to evaluate induced acrosomal exocytosis at $150 \mathrm{~min}$. At each time point, acrosomal status (presence (blue band stained in sperm head) or absence of acrosome (pink head)) was evaluated by the HOS-Spermac method in motile spermatozoa (Herrero et al. 1998). Briefly, $20 \mu \mathrm{L}$ of the sperm suspensions was transferred to Eppendorf tubes containing $200 \mu \mathrm{L}$ hypoosmotic medium $(\mathrm{HOSM}=0.735 \mathrm{~g}$ 
sodium citrate and $1.351 \mathrm{~g}$ fructose in $100 \mathrm{~mL}$ distilled water) and incubated for one hour at $37^{\circ} \mathrm{C}$. Then, spermatozoa were pelleted by centrifugation at $500 \mathrm{~g}$ for $5 \mathrm{~min}$ and resuspended in $20 \mu \mathrm{L}$ HOSM. Ten microliters of this suspension were placed on a microscope slide and allowed to dry. Immediately after drying, slides were fixed for one hour in 5\% formaldehyde in phosphate buffer ( $\mathrm{v} / \mathrm{v})$, washed with distilled water, stained with the Spermac procedure and allowed to dry. Slides were examined in a bright field microscope at $\times 100$, under immersion. Viability and the presence of the acrosomal cap were assessed in at least 200 spermatozoa per control and treated males (6 mice per group). Results were expressed as mean percentage reacted spermatozoa \pm S.E.M.

\section{In vitro decondensation}

After $120 \mathrm{~min}$ of capacitation, in vitro sperm nuclear decondensation was induced in the presence of $100 \mu \mathrm{mol} / \mathrm{L}$ glutathione $(\mathrm{GSH})$ plus $4.6 \mu \mathrm{mol} / \mathrm{L}$ heparin (Hep, 13,500 kDa, $170 \mathrm{lU} / \mathrm{mg}$ ) for 30 and $60 \mathrm{~min}$. Controls consisted of parallel incubations with GSH or heparin alone. After each time period, a $30-\mu \mathrm{L}$ aliquot of the sperm suspension was removed and fixed with an equal volume of $2.5 \%$ glutaraldehyde in phosphate-buffered saline (PBS). Aliquots of $5 \mu \mathrm{L}$ spermatozoa were stained (Hoechst 33342, $0.5 \mu \mathrm{g} / \mathrm{mL}$, Sigma) or not, and transferred onto a slide to assess nuclear status under phase contrast and fluorescence microscopy (Olympus $\mathrm{CH}_{2}$ microscope at 40x). Spermatozoa were classified as unchanged $(U)$, moderately decondensed (M) or grossly decondensed (G) (Sanchez et al. 2013). At least 200 cells were evaluated in each category. Total sperm decondensation achieved was determined as the total \% M plus \% G (\% M+G) and data were expressed as mean \% values \pm standard deviation of the mean (S.D.M.) for 5 males per group.

\section{In vitro fertilization (IVF)}

Male mice were killed by cervical dislocation on the morning of day 15 of ethanol treatment, to perform IVF-experiments (Cebral et al. 1997). The epididymides of one male were dissected and the caudae placed into $300 \mu \mathrm{L}$ drop of IVFM$3 \%$ BSA, overlaid with mineral oil to collect the sperm suspension, as described earlier. Spermatozoa were then incubated for $90 \mathrm{~min}$ at $37^{\circ} \mathrm{C}$ and $5 \% \mathrm{CO}_{2}$ in air, to allow for capacitation.

Adult female mice were induced to superovulate with $5 \mathrm{IU}$ of pregnant mare's serum gonadotrophin (PMSG, Sigma) given at 18:00 h on day 12 of ethanol treatment, and $5 \mathrm{IU}$ of human chorionic gonadotrophin (hCG, Sigma) $48 \mathrm{~h}$ later. Females were killed by cervical dislocation 16-17 h after hCG injection when ethanol treatment was stopped (day 15 of treatment). Both oviducts were removed and placed in PBS. One oocytecumulus complex (OCC) was released from each ampulla into a 50- $\mu$ L drop of IVFM-BSA (one cumulus mass per drop) and overlaid with mineral oil.

One OCC from one female was inseminated with $1-2 \times 10^{5}$ spermatozoa/mL from a control male, and the second OCC of the same female was inseminated with the same concentration of spermatozoa from a treated male. With this experimental design, 7 IVF-experiments were performed, with a total of 3 females and one control and one ethanol-treated male per experiment, and with a final number of 21 females and 7 control and 7 treated males.

The timing of IVF events was evaluated in control and treated males after examination of oocytes at 2.5, 3.5 and $4.5 \mathrm{~h}$ of in vitro insemination. Oocytes were washed to remove cumulus cells and adherent spermatozoa and were then fixed with $2 \%$ paraformaldehyde and incubated for $10 \mathrm{~min}$ with Hoechst $33342(0.5 \mu \mathrm{g} / \mathrm{mL})$ in PBS. After washing (PBS), oocytes were examined under phase contrast and fluorescence microscopy (Nikon ActurusXT microdissection microscope) and classified as follows (Fig. 1): (a) fertilized oocytes: Telophase II (Te II) oocytes with second polar body (2PB's) and a decondensed head in the ooplasm $(\mathrm{DH})$; oocytes with $2 \mathrm{~PB}^{\prime} \mathrm{s}+$ female pronucleus $(\mathrm{fPN})+$ male pronucleus $(\mathrm{mPN})$; (b) unfertilized oocytes: metaphase II-arrested oocytes (Me II); Me II-arrested oocytes with adhered spermatozoa (As); oocytes with $2 \mathrm{~PB}^{\prime}$ s and fPN (spontaneously activated oocytes with second polar body and one female pronucleus); fragmented oocytes.

The number of fertilized and unfertilized oocytes, the number of oocytes with a decondensed sperm head and the number of oocytes with 2PB's and 2PN's were recorded for each control and treated male at each time point studied. Results were expressed as the mean \% oocytes in each category \pm S.D.M.

\section{Statistical analyses}

Reported values of control and treated derived samples were expressed as mean \pm standard deviation of the mean (S.D.M.) or standard error of the mean (S.E.M.), as stated in text. Differences between group means were statistically analyzed by one-way analysis of variance (ANOVA) and Student's $t$ test. Differences between groups were considered statistically significant when $P<0.05$. Analyses were performed with GraphPad InStat v2.05a (GraphPAD Software).

\section{Results}

\section{Male mouse body weight, food and liquid consumption and blood alcohol concentration after sub-chronic ethanol treatment}

Given that changes in body weight and patterns of liquid and food intake have not been previously monitored in a model of male sub-chronic 15\% alcohol intake, and since ethanol consumption could alter these parameters, they were monitored daily for the whole duration of the treatment. Treated males consumed significantly lower quantities of food than controls ( $P<0.05$, Table 1$)$, but the total calorie intake was similar in both groups. Treated males consumed $30 \mathrm{~g} / \mathrm{kg} /$ day ethanol and had $30.3 \%$ EDC (Table 1). No differences in body weight between treated males and controls were registered either at the beginning or at the end of ethanol treatment. The level of BAC in treated males was $15-60 \mathrm{mg} / \mathrm{dL}$, and no alcohol was detected in control males. 
2 PB's + Tell + DH
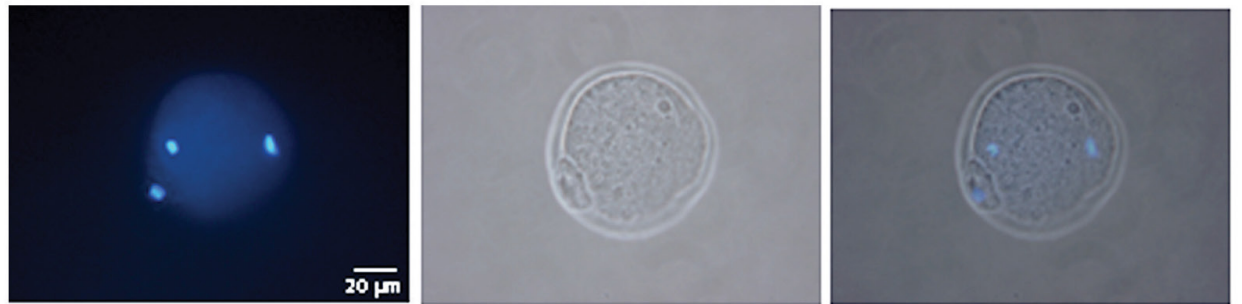

2 PB's + fPN + mPN
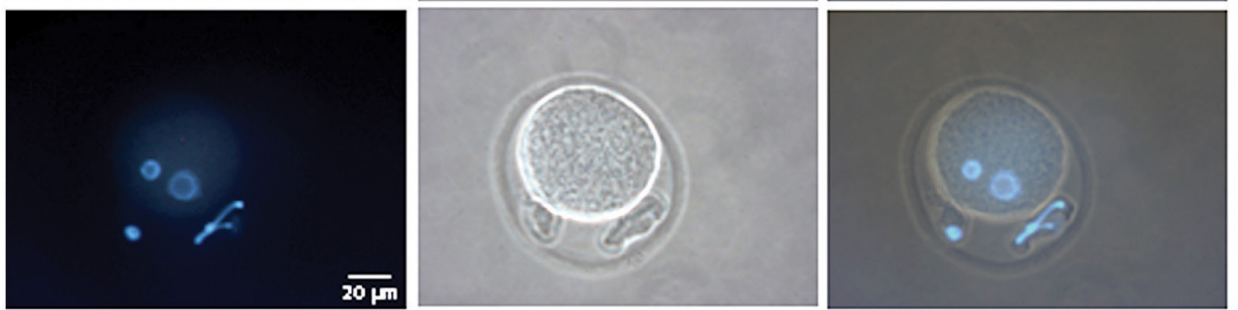

Me II
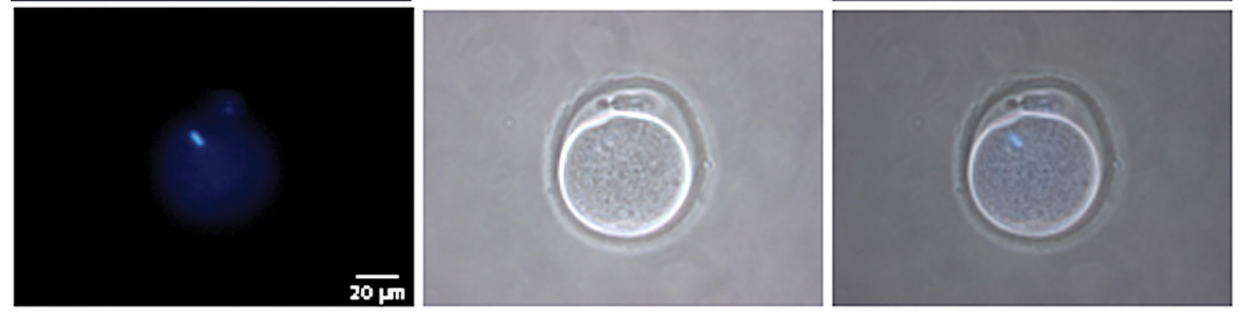

Mell + As
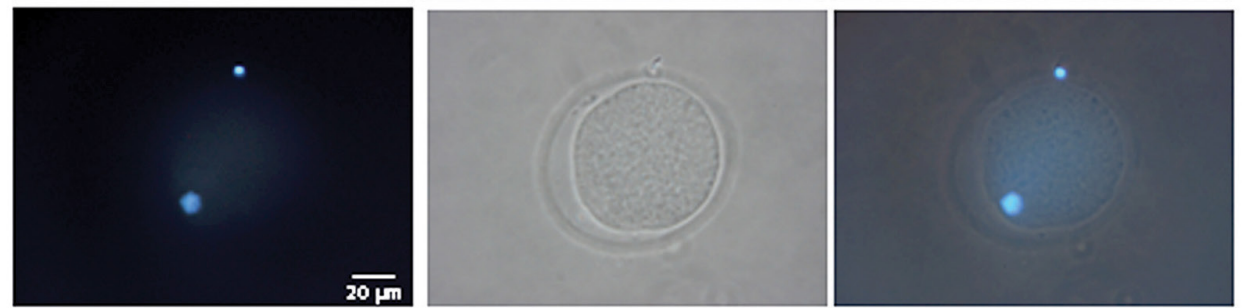

2PB + fPN
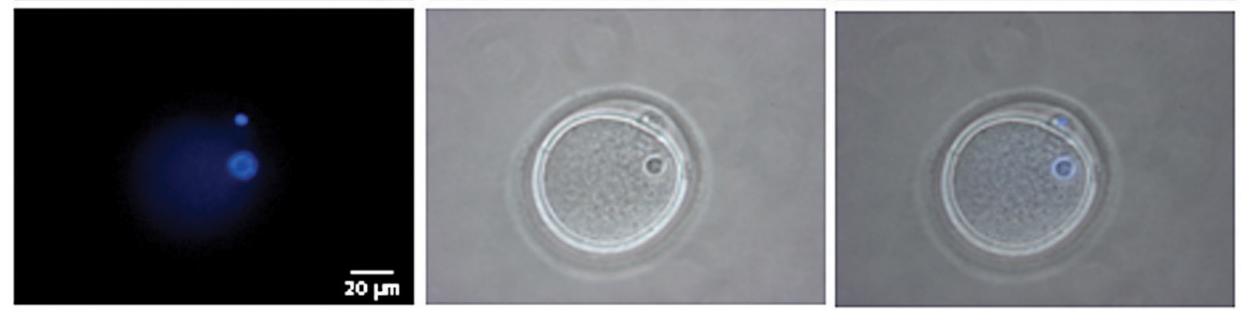

Fragmented
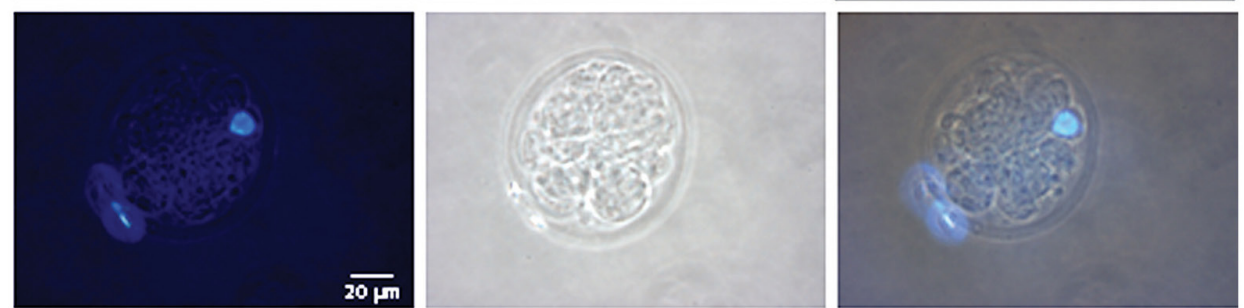

Figure 1 CF-1 murine oocyte evaluation after in vitro fertilization. After in vitro fertilization (IVF), oocytes were examined under phase contrast and fluorescence microscope and classified as: telophase oocytes (Te II) with second polar body and a decondensed sperm head in the ooplasm $(2 \mathrm{~PB}$ 's $+\mathrm{Te} \mathrm{II}+\mathrm{DH})$; oocytes with female and male pronucleus (2PB's +fPN $+\mathrm{mPN})$; metaphase II-arrested oocytes (Me II); Me II-arrested oocytes with adhered spermatozoa (Me II+As); spontaneously activated oocytes (2PB's +fPN) and fragmented oocytes. First column: nuclear Hoechst fluorescence; second column: phase contrast; third column: merge. 
Table 1 Alcohol intake pattern and body weight in control and treated males.

\begin{tabular}{lcc} 
& $\begin{array}{c}\text { Control males } \\
(n=15)\end{array}$ & $\begin{array}{c}\text { Treated males } \\
(n=15)\end{array}$ \\
\hline Food intake $(\mathrm{g} / \mathrm{kg} / \mathrm{day})$ & $200.0 \pm 16.9$ & $163.0 \pm 11.2^{*}$ \\
Liquid intake $(\mathrm{mL} / \mathrm{kg} /$ day $)$ & $222.5 \pm 33.8$ & $200.1 \pm 19.7$ \\
Food calories $(\mathrm{kcal} / \mathrm{kg} /$ day $)$ & $610.1 \pm 50.7$ & $479.0 \pm 33.6^{*}$ \\
Liquid calories $(\mathrm{kcal} / \mathrm{kg} /$ day $)$ & - & $213.1 \pm 20.9$ \\
Total calories $(\mathrm{kcal} / \mathrm{kg} /$ day $)$ & $610.1 \pm 51.7$ & $692.0 \pm 54.6$ \\
Ethanol intake $(\mathrm{g} / \mathrm{kg} /$ day $)$ & - & $30 \mathrm{~g} / \mathrm{kg} /$ day \\
$\%$ EDC & & $30.3 \%$ \\
Body weight & & \\
Initial weight $(\mathrm{g})$ & $34.4 \pm 0.56$ & $34.1 \pm 0.8$ \\
Final weight $(\mathrm{g})$ & $35.2 \pm 0.5$ & $34.0 \pm 1.0$ \\
\hline
\end{tabular}

Mean daily food and liquid intake $(\mathrm{g}, \mathrm{mL} / \mathrm{kg} /$ day) and body weight $(\mathrm{g})$ were assessed at the beginning, during and at the end of sub-chronic $15 \%$ ethanol administration, in both, control (no ethanol

administration) and treated males. Energy intake was calculated from food and ethanol consumption ( $\mathrm{kcal} / \mathrm{kg} /$ day). Mean ethanol intake is expressed in $\mathrm{g} / \mathrm{kg} /$ day and \% EDC (percentage of ethanol-derived calories). Values are expressed as mean \pm S.E.M.

${ }^{*} P<0.05$ vs control males, Student's $t$ test, 15 animals per group.

\section{Capacitation, hyperactivation and acrosomal exocytosis after sub-chronic alcohol consumption}

Up to date, there is no evidence on the effects of subchronic moderate alcohol consumption on sperm capacitation and associated parameters in the adult mouse model. Initially, we analyzed protein phosphorylation on tyrosine residues, considered by several authors as a possible indicator of sperm capacitation (Jabbari et al. 2009). Accordingly, we analyzed the pattern of tyrosine phosphorylation in spermatozoa from alcohol-treated mice and controls, following incubation in capacitating conditions. Figure 2A shows a Western blot analysis of the protein pattern for phosphotyrosine expression, after $120 \mathrm{~min}$ of incubation under capacitating conditions. A different pattern of phosphorylated bands could be observed between non-capacitated and capacitated spermatozoa from both control and treated groups. However, the same bands of MW p95/116 (hexokinase), 72/73, 50/51, 26/27 and 20/21 kDa, were observed under capacitating conditions in both control and treated animals, indicating that alcohol consumption did not affect the expression of phosphorylated proteins after capacitation.

Although we did not find noticeable differences in the pattern of protein tyrosine phosphorylation between control and treated animals, we decided to study hyperactivation and acrosome reaction, both capacitation-related phenomena, since other factors could be involved in their regulation. We first analyzed sperm motility following incubation in vitro in capacitating conditions. In treated males, the percentage of motile spermatozoa was not significantly different than that of control animals (Fig. 2B). However, hyperactivation was significantly reduced in spermatozoa from treated males as compared to controls, at 60 and
120 min of capacitation (T60 min: $P<0.05$, T120 min: $P<0.05$, Fig. 2C).

Subsequently, we analyzed acrosomal exocytosis in motile spermatozoa in both groups. The percentage of spermatozoa that underwent spontaneous loss of acrosomal content was significantly reduced in treated males at 120 and $150 \mathrm{~min}$ of capacitation as compared to control males (T120 min: $P<0.01 ;$ T150 min: $P<0.001$, Fig. 2D). In addition, while control-derived spermatozoa showed an increase $(P<0.05)$ in acrosomal exocytosis after exposure to $15 \mu \mathrm{M}$ progesterone at $150 \mathrm{~min}$ of capacitation, the percentage acrosome reaction in spermatozoa from treated males was significantly reduced in comparison to control value $(P<0.001$, Fig. 2D).

\section{In vitro oocyte penetration and sperm head decondensation kinetics after sub-chronic alcohol consumption}

IVF studies allow for a detailed analysis of sperm penetration and kinetics of head decondensation at early post-insemination times. The frequencies of fertilized and unfertilized oocytes at 2.5, 3.5 and $4.5 \mathrm{~h}$ post-in vitro insemination were studied following 15 days of $15 \%$ alcohol administration to CF-1 male mice. The mean percentage of fertilized oocytes (with $2 \mathrm{~PB}^{\prime}$ s and female PN plus decondensed head or with 2PNs, Fig. 1) significantly increased from 2.5 to $3.5 \mathrm{~h}$ but not from 3.5 to $4.5 \mathrm{~h}$ after in vitro insemination, both in control and treated males. However, at each IVF time point evaluated, the percentage of fertilized oocytes was significantly higher in treated vs control males $(P<0.001$, Fig. 3A). Consequently, at each time point, the percentage of unfertilized oocytes was significantly reduced in treated vs control males $(P<0.001$, Fig. $3 \mathrm{~B})$.

To elucidate whether the increased percentage of fertilized oocytes of treated males was due to a change in the time-pattern of sperm decondensation, we analyzed sperm decondensation kinetics after IVF in both control and treated groups. The percentage of fertilized oocytes with a decondensed head (Fig. 1) significantly increased in treated males at $2.5 \mathrm{~h}$ of in vitro insemination $(P<0.001)$, but reduced at $3.5 \mathrm{~h}$, when compared to control animals $(P<0.001$, Fig. $4 \mathrm{~A})$. However, at 3.5 and $4.5 \mathrm{~h}$ after insemination, the mean percentage of fertilized oocytes with 2PB's and 2PN's (Fig. 1) in treated males was significantly increased compared to control males $(P<0.001$, Fig. 4B).

We have previously shown (Sanchez et al. 2013) that mouse sperm decondensation can be achieved, in vitro, using glutathione (GSH) and heparin and, thus, we further analyzed in vitro decondensation kinetics in both control and treated males. Figure 5 shows the percentage of decondensed spermatozoa from control and treated males in the presence of GSH and/or $4.6 \mu \mathrm{M}$ heparin. As expected, the addition of GSH or heparin alone did 


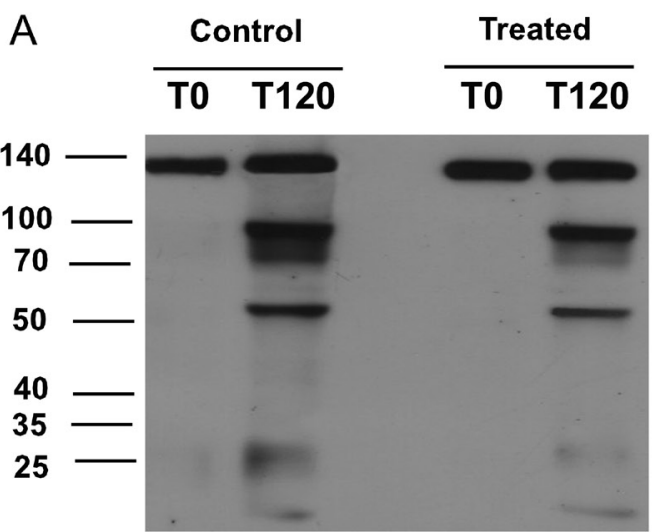

B

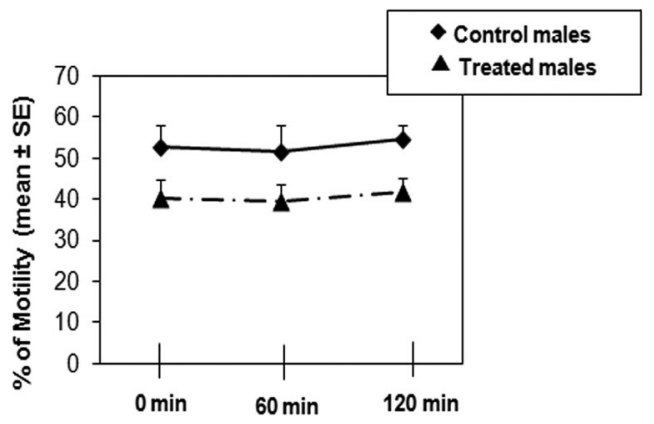

C
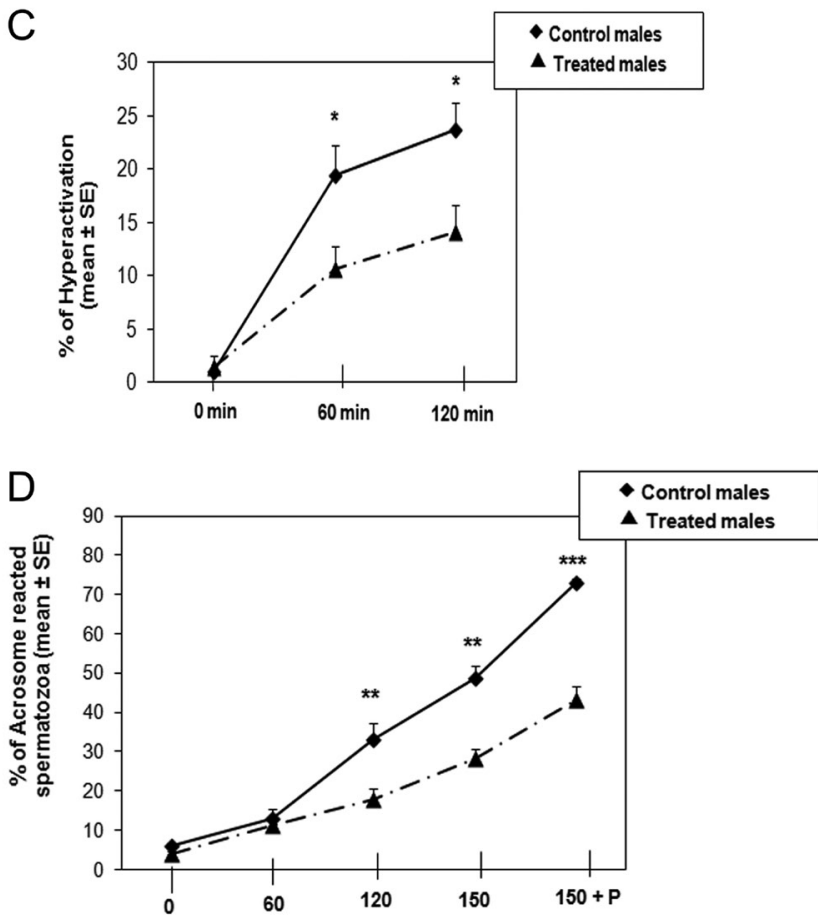

Figure 2 Sperm capacitation following sub-chronic alcohol consumption in CF-1 mice. (A) Analysis of tyrosine protein phosphorylation in spermatozoa from control and treated males. Protein tyrosine phosphorylation of caudal epididymal mouse sperm was evaluated after incubating $2 \times 10^{6}$ spermatozoa $/ \mathrm{mL}$ in capacitating conditions for $120 \mathrm{~min}$. Proteins were extracted and separated by $10 \%$ SDS-PAGE and identified using a specific anti-phosphotyrosine antibody. Both control and treated males not produce decondensation, but GSH plus heparin induced sperm decondensation in both control and treated males. At $60 \mathrm{~min}$ of incubation, the percentage of decondensed spermatozoa from treated males was significantly increased as compared to control animals $(P<0.05$, Fig. 5).

\section{Effects of sub-chronic alcohol consumption on sperm morphology}

Given that the changes in sperm functional parameters, oocyte penetration and sperm decondensation during fertilization could result from morphological alterations of the sperm head, we evaluated changes in acrosome morphology, head and midpiece shape and assessed the frequency of abnormal spermatozoa after sub-chronic ethanol intake. In contrast to morphologically normal sperm heads (Fig. 6A), an abnormal neck insertion (Fig. 6B), a sperm head with abnormal (smaller or absent) acrosome (Fig. 6C), a decreased head size and altered head shape (round; Fig. 6C) and a spermatozoon with cytoplasmic droplet and abnormal head shape (Fig. 6D) were recorded as morphological abnormal. Treated males had a significantly higher percentage of abnormal sperm head morphology as compared to controls $(P<0.001$, Table 2$)$.

\section{Discussion}

The aim of the present study was to analyze the effects of short-term moderate alcohol consumption on sperm

showed a similar pattern of protein phosphorylation when sperm cells were incubated under capacitating conditions for $120 \mathrm{~min}$. Left lane: molecular weight markers. T0: non-capacitated spermatozoa. A representative Western blot membrane is shown. The experiment was performed 5 times, with similar results. A total of 5 animals per group were used. ( $\mathrm{B}$ and $\mathrm{C}$ ) Motility and hyperactivation during capacitation in control and treated males. Murine spermatozoa were recovered from epididymal caudae of control (continuous line) and treated males (dotted line) and sperm motility \% (B) and hyperactivation \% (C) were determined. Values are expressed as mean \pm standard error of the mean (S.E.M.). Percentages of hyperactivated spermatozoa were significantly diminished in treated males vs controls at 60 and 120 min of capacitation $\left({ }^{*} P<0.05,6\right.$ males per group, Student's $t$ test). (D) Spontaneous and induced acrosomal exocytosis in control and treated males. The presence or absence of acrosomal vesicle was evaluated at 0,60, 120 and $150 \mathrm{~min}$ of capacitation by the HOSSPERMAC procedure, as indicated in Materials and methods. At $120 \mathrm{~min}$, progesterone $(15 \mu \mathrm{M}$ final concentration) was added to sperm incubation to induce acrosome reaction $(150+\mathrm{P})$. Acrosome reaction $\%$ was calculated as number of acrosome-reacted sperm over total number of vital spermatozoa (hypoosmotic test). Results are expressed as mean \pm S.E.M. Spermatozoa from treated males (dotted line) presented a significant decrease in spontaneous acrosome reaction at 120 and 150 min of capacitation $(* * P<0.01)$ and progesterone-induced acrosome reaction at $150 \mathrm{~min}(* * * P<0.001)$ as compared to control values (continuous line) ( 6 males per group, Student's $t$ test). 
capacitation and IVF events in the outbred adult mouse, with emphasis on sperm head decondensation.

The effects of alcohol consumption in humans are not easy to assess because of the difficulties in comparison of populations, mainly due to variations in the pattern of alcohol intake. Because of intrinsic differences between humans and mice, no single mouse model can represent all features of a complex human trait such as alcoholism. Our results in an outbred mouse model demonstrated that short-term moderate ethanol consumption leads to altered sperm fertility, in accordance with other ethanol mouse models (Anderson et al. 1983, Morton et al. 2014, Wieczorek et al. 2015). One important feature of the present ethanol intake model in drinking water is that CF-1 mice reliably drank ethanol to moderate BAC levels (range 15-60 mg/dL) and consumed $30 \mathrm{~g}$ ethanol/ $\mathrm{kg}$ body weight daily, similar to other paradigms of
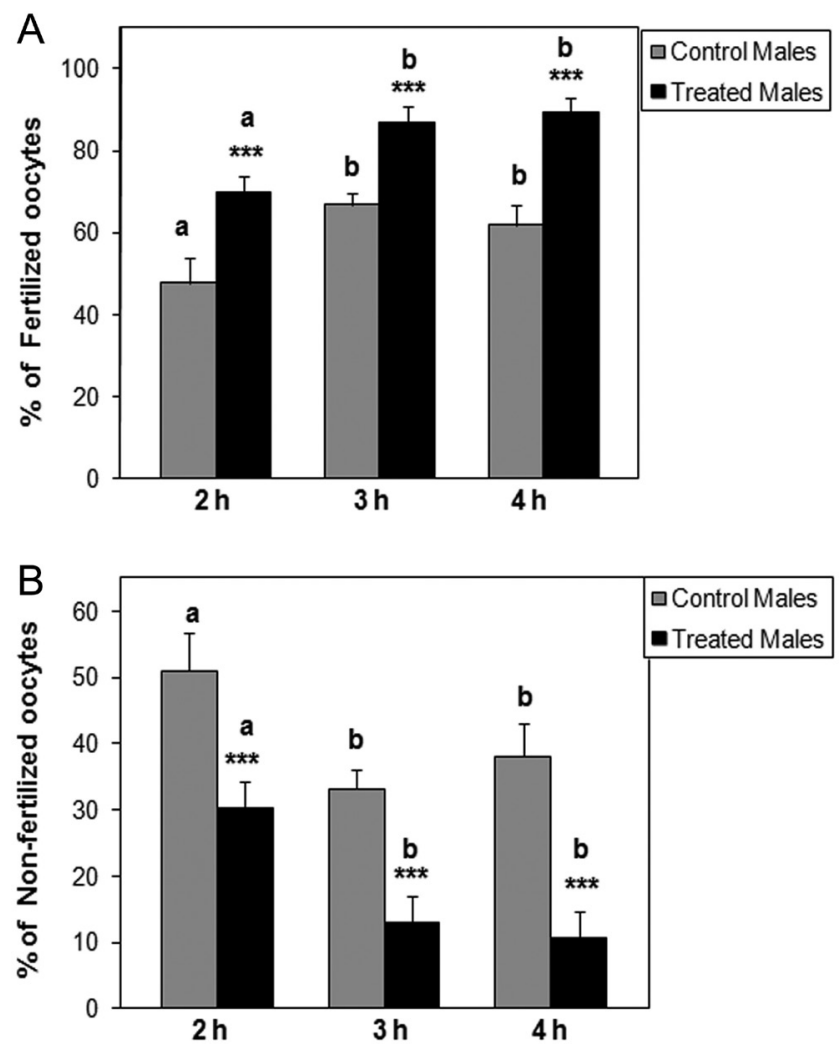

Figure 3 Frequency of fertilized and unfertilized oocytes after IVF in control and treated males. (A) Fertilized oocytes: oocytes with 2PB's, female PN and a decondensed sperm head. At 2.5, 3.5 and $4.5 \mathrm{~h}$ after insemination, percentage of fertilized oocytes in the alcoholtreated group was significantly increased with respect to control (***P<0.001, Student's $t$ test). (B) Unfertilized oocytes: metaphase II-arrested oocytes, activated oocytes with $2 \mathrm{~PB}^{\prime}$ s and a female pronucleus or with adhered spermatozoa. Percentage of unfertilized oocytes in the alcohol-treated group was significantly reduced with respect to control $\left({ }^{* * *} P<0.001\right.$, Student's $t$ test). Different letters above group bars denote significant differences between groups (A vs B: $P<0.01$, ANOVA, Student-Newman-Keuls test; 7 males per group). Results are expressed as mean \pm standard deviation of the mean (S.D.M.). ethanol drinking intake with 10, 20 or $30 \%$ ethanol that produce an average BAC of approximately $1.6 \mathrm{mg} / \mathrm{mL}$ (Rhodes et al. 2005). With this value of moderate BAC levels, we found changes in fertilization outcome even though other authors did not find effects on reproductive parameters (Ogilvie et al. 1997, Bonthius et al. 2002, Zhang \& Chong 2016). Furthermore, although the value of $30.3 \%$ EDC obtained was relatively low compared to value ranges previously reported (Willis et al. 1983, Abel \& Moore 1987, Shirai \& Ikemoto 1992, Mittleman et al. 2003), we observed not only an effect on fertilization but also altered sperm morphology and capacitation parameters.

In addition to ethanol concentration and routes of administration, ethanol effects on male reproductive function depend on the duration of exposure. In this work, we evaluated whether a moderate $15 \%$ ethanol concentration in the drinking water administered for 15 days had a deleterious effect on sperm morphology,
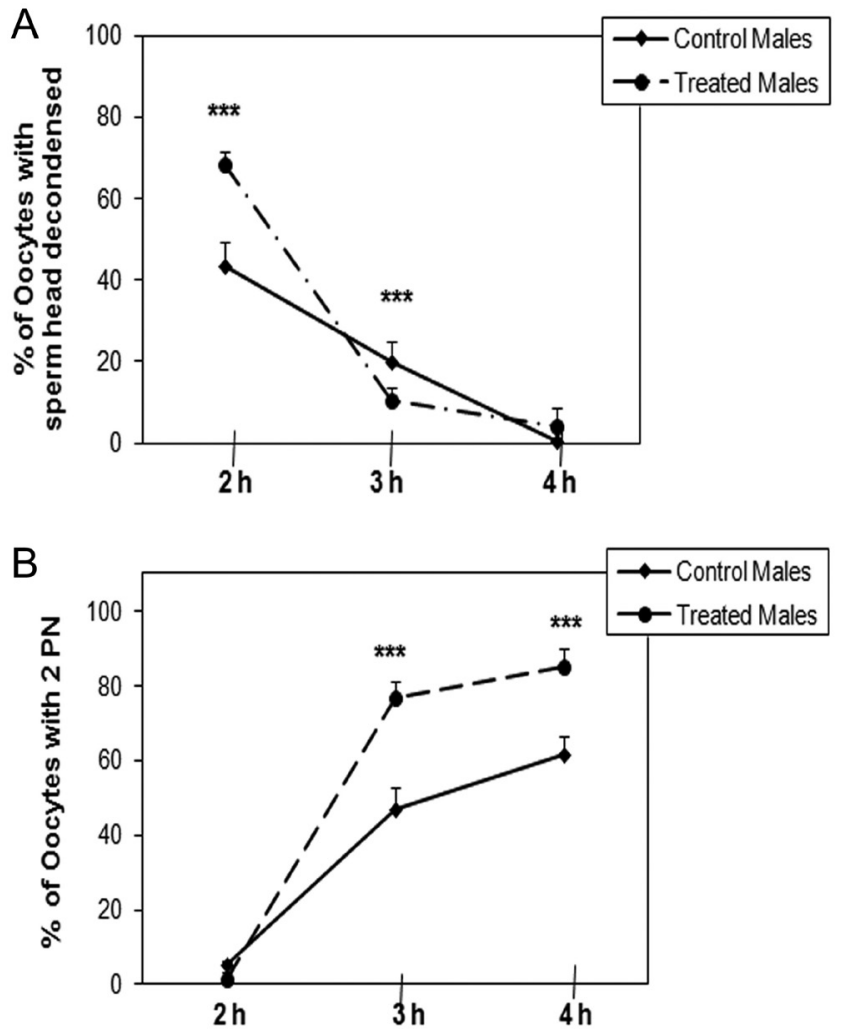

Figure 4 Sperm head decondensation and pronuclear formation during in vitro fertilization in control and treated males. At 2.5, 3.5 and $4.5 \mathrm{~h}$ after insemination, fertilized oocytes stained with Hoechst 33342 were analyzed for nuclear evaluation, as described in Materials and methods. (A) Kinetics of sperm head decondensation in each group was determined by calculating the percentage of oocytes with 2PB's, female pronucleus and a decondensed sperm head. (B) Kinetics of pronuclear formation in each group was determined by calculating the percentage of oocytes with 2PB's and 2PN's. ***P$P<0.001$ vs control males, Student's $t$ test, $n=7$ males. Results are expressed as mean \pm S.D.M. 


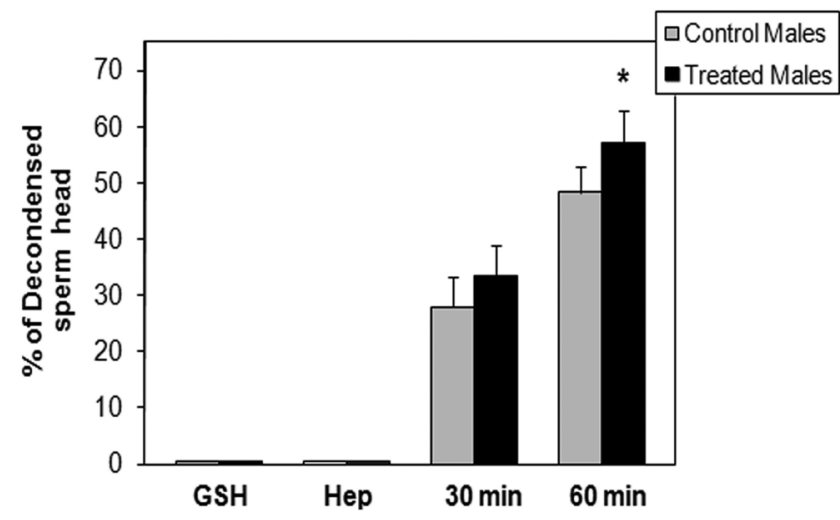

Figure 5 Sperm head decondensation in control and treated males. In vitro nuclear decondensation was analyzed following incubation of spermatozoa from each group in glutathione (GSH) plus heparin $4.6 \mu \mathrm{M}$ (Hep) at $120 \mathrm{~min}$ of capacitation and visualized by Hoechst staining. Negative controls: spermatozoa incubated with GSH or heparin alone. The percentage of moderately decondensed and grossly decondensed spermatozoa was analyzed at 30 and 60 min of incubation. At $60 \mathrm{~min}$, sperm head decondensation in treated males was significantly higher than in controls $\left({ }^{*} P<0.05, n=8\right.$ males, Student's $t$ test). Results are expressed as mean \pm S.D.M.

sperm functional parameters and IVF dynamics. Considering that during mouse spermatogenesis (35 days duration) (Creasy \& Chapin 2014), the spermatid elongation phase is about 8.5 days long, and that it takes an additional $4-5$ days for sperm to reach the caudal epididymis (De Grava Kempinas \& Klinefelter 2014), epididymal caudal spermatozoa were exposed to ethanol intake during the spermatid elongation phase in the seminiferous epithelium for about 10 days and during sperm maturation for an additional 5 days of epididymal transit, accounting for a 15-day ethanol exposure. Since chromatin head condensation takes place both during spermatid elongation in the testis and epididymal sperm maturation (Fujii \& Imai 2014), the present short period of ethanol exposure could affect sperm head condensation.

The mechanisms involved in ethanol-induced infertility regarding alterations in sperm motility, capacitation or nuclear decondensation during IVF remain poorly understood (Pajarinen et al. 1996, Auger et al. 2001, Martini et al. 2004, Muthusami \& Chinnaswamy 2005). Contrary to other reports found in literature, in which a decrease in sperm motility from alcohol-treated animals is usually described (Condorelli et al. 2015), in the present model, ethanol ingestion was not able to reduce sperm motility. However, in treated males, there was a lower percentage of hyperactivated spermatozoa than in controls at 60 and 120 min of capacitation. Such an observation would indicate that sperm from treated males show alterations in the biochemical and physiological events, leading to hyperactivated motility, probably related to the increased frequency of morphological abnormalities of the flagellum, possibly associated to abnormal axoneme and periaxoneme.

Since tyrosine phosphorylation of different proteins is usually associated with sperm capacitation (Visconti et al. 1995, 2011, Bailey et al. 2010), we monitored the pattern of tyrosine phosphorylation in control and treated males. Under our experimental conditions, tyrosine phosphorylated proteins were detected in capacitated CF-1 mouse spermatozoa, but there was no evident difference between phosphorylation patterns in control and treated groups.

When acrosomal exocytosis was evaluated following $120 \mathrm{~min}$ of capacitation, spontaneous acrosome reaction was lower in spermatozoa from treated males in comparison to control animals. The decrease in spontaneous acrosomal exocytosis persisted at $150 \mathrm{~min}$ when spermatozoa were challenged with progesterone to evaluate induced acrosomal exocytosis. This reduced

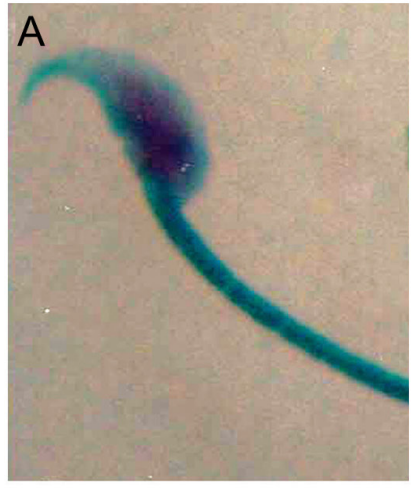

Normal

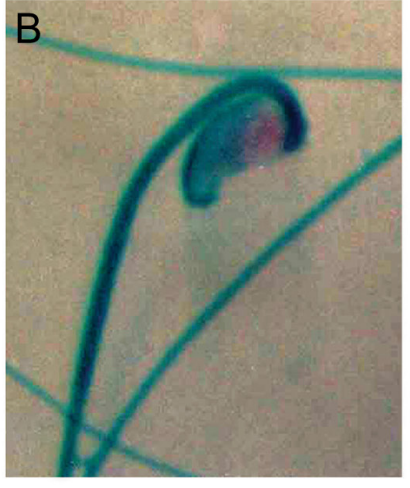

Abnormal head and neck

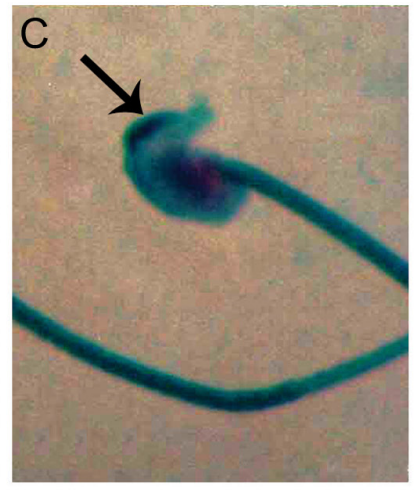

Abnormal head and acrosome

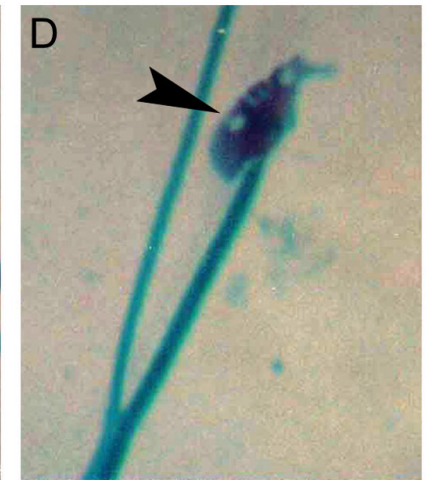

\section{Abnormal head without acrosome}

Figure 6 Morphological sperm abnormalities in CF-1 mouse. (A) Normal head and flagellum. (B) Abnormal head shape with abnormal neck insertion. (C) Abnormal round head with a very small and delocalized abnormal acrosome formation (arrow). (D) Abnormal sperm head with cytoplasm droplet (arrow head) and absence of acrosome. Scale bar: $10 \mu \mathrm{m}$. 
Table 2 Frequency of abnormal spermatozoa in control and treated males.

\begin{tabular}{lccc}
\hline Groups & Normal sperm (mean \% \pm S.D.M.) & Abnormal head (mean \% \pm S.D.M.) & Abnormal flagellum (mean \% \pm S.D.M.) \\
\hline Control males $(n=9)$ & $84.13 \pm 1.63$ & $6.9 \pm 0.07$ & $8.9 \pm 0.8$ \\
Treated males $(n=9)$ & $72.5 \pm 2.6^{* * *}$ & $10.5 \pm 1.52^{* *}$ & $16.8 \pm 2.1^{* * *}$ \\
\hline
\end{tabular}

Abnormal spermatozoa from control and treated mice were classified as having amorphous head, neck, and/or midpiece defects and/or an abnormal flagellum. Values are expressed as mean \pm S.D.M.

${ }^{* *} P<0.01,{ }^{* * *} P<0.001$, vs control males, Student's $t$ test.

acrosomal reaction could be indicative of modifications in the sperm membrane, with possible alteration of progesterone receptors, and/or modification of sperm membrane stability that renders the spermatozoon resistant to the action of progesterone. Ethanol can interfere with membrane permeability by disturbing lipid fluidity due to direct oxidation of proteins (Christova et al. 2004), and changes in sperm cholesterol content, among other factors, are known to be involved in capacitation (Florman \& Ducibella 2006, Bailey et al. 2010, Evans et al. 2012). The short-term moderate ethanol exposure in these experiments could be inducing similar molecular alterations in the sperm head that could in turn result in a reduced acrosome reaction. Furthermore, we believe that both reduced acrosomal exocytosis and increased percentage of morphologically abnormal sperm heads are alcohol-associated effects in treated mice.

Thus far, our results suggested that sub-chronic moderate ethanol ingestion affected two crucial events prior to fertilization, hyperactivation and acrosomal exocytosis, and also sperm head morphology. It was tempting to hypothesize that this ethanol ingestion paradigm could also alter later events in fertilization, such as ZP penetration, sperm adhesion and fusion to the oolemma, oocyte penetration, and even sperm nuclear decondensation and male pronucleus formation in the ooplasm. Spermatozoa from sub-chronic-ethanoltreated males showed an increased fertilization rate, from the earliest time point examined up to $4.5 \mathrm{~h}$ following in vitro insemination. Previous reports suggested that ethanol exposure in males negatively affects fertility parameters through the inhibition of capacitation and acrosomal exocytosis (Anderson et al. 1983, Rossi et al. 2011, Nicolau et al. 2014, Wdowiak et al. 2014) or by alteration of both in vitro and in vivo fertilization (Cebral et al. 1997). In this study, moderate ethanol administration for 15 days to CF-1 mice produced an increase in the number of oocytes with a decondensed sperm head at $2.5 \mathrm{~h}$ of insemination which descended abruptly at $3.5 \mathrm{~h}$ of IVF when the decondensed nucleus developed into the male pronucleus. These differences in nuclear decondensation kinetics during IVF between control and treated males suggest an acceleration of the process of sperm nuclear decondensation and formation of the male pronucleus in mice sub-chronically treated with $15 \%$ ethanol.

Sperm head decondensation seems to be one of main fertility parameters affected in treated males. Differences found in sperm head decondensation kinetics during IVF between treated males and controls led us to analyze the possible effects of ethanol exposure on in vitro sperm decondensation of capacitated spermatozoa in the presence of GSH plus heparin. Percentage of decondensed sperm was higher in treated males compared to controls, suggesting once more that ethanol exposure leads to an acceleration of sperm nuclear decondensation.

Chromatin remodeling, which occurs during differentiation of elongating spermatids and sperm maturation, involves the replacement of histones by protamines, and is a prerequisite for adequate sperm nuclear function and structure. Redox reactions contribute to this process by sulfoxidation of protamines with the participation of glutathione peroxidase (GPX), enzyme that specifically catalyzes the detoxification of hydrogen peroxide. This enzyme, which is present at a considerable quantity in the sperm midpiece, is the main contributor to sperm chromatin stability and the maintenance of mitochondrial membrane potential. Spermatozoa of mice lacking sperm nuclear GPX activity display an abnormal nucleus, showing delayed and/or defective nuclear compaction, nuclear instability and DNA damage. Sperm from nuclear GPX4-knockout mice are more prone to decondense during epididymal maturation than those from wildtype mice and also show significant reductions in forward motility and mitochondrial membrane potential and a structurally abnormal flagellum at the midpiece with swelling of the mitochondria (Fujii \& Imai 2014). Given that the present ethanol treatment resulted in an increase in morphologically abnormal spermatozoa, decreased hyperactivation and acrosomal reaction and dysregulation of sperm head decondensation kinetics, we propose that ethanol exposure is hindering the expression and/or activity of GPX in the developing ethanol-exposed spermatozoon. Our laboratory has recently reported an increase in reactive oxygen species and oxidative stress, similar to a high oxidative status, in reproductive-gestational tissues following alcohol exposure (Coll et al. 2018). A similar effect could be also induced by ethanol exposure during sperm development/maturation in the testis and epididymis and thus contribute to altered sperm compaction. Our present findings go along with previous reports in the literature stating that ethanol consumption produced spermatozoa with a less compacted chromatin (Talebi et al. 2011), and induced abnormalities in external and acrosomal membranes, in chromatin packaging and 
altered the nuclear integrity of spermatozoa (Eid et al. 2002, Lewis-Jones et al. 2003, Gaur et al. 2010, Cebral et al. 2011, Joo et al. 2012, Anifandis et al. 2014).

Taken together, the results presented in this paper suggest that sub-chronic ingestion of alcohol negatively affects sperm morphology, capacitation parameters and IVF dynamics. The identification of changes in sperm morphology and function and fertilization events, following short-term ethanol consumption in the male mouse, will allow us to develop new studies aimed at understanding the mechanisms underlying the short-term ethanol-induced sperm effects and their consequences on early embryo development.

\section{Declaration of interest}

The authors have no conflict of interest. All co-authors have read, approved and concur with the submitted manuscript. The authors have ensured the integrity of the work. There is no conflict of interest that could be perceived as prejudicing the impartiality of the research reported. There is no potential conflict of interest with any financial aid.

\section{Funding}

This work was supported by grants from Universidad de Buenos Aires (JCC: UBACYT 20020100101034), ANPCYT (EC: PICT 2008-2210; JCC: PICT 2012-2489), CONICET (EC: PIP 5917; JCC: PIP 464) and the generous donation by Fundación Honorio Bigand.

\section{Author contribution statement}

M C S was involved in experimental design and procedures, data analysis and interpretation. $V F$ and $C S$ played a role in experimental procedures and manuscript revision. $C \mathrm{G}$ and $\mathrm{M}$ Y C were involved in the phosphotyrosine experiments. $\mathrm{L} C$ took part in data analysis and interpretation as well as in the final revision of the manuscript, J C C and E C were involved in concept and experimental design, data analysis, interpretation, article draft and revision of manuscript.

\section{Acknowledgements}

The authors wish to thank the invaluable assistance of $\mathrm{Dr}$ Clarisa Marin-Briggiler and Dr Judith Toneatto in the analysis of phosphotyrosine experiments. They would also like to thank Universidad de Buenos Aires, Consejo Nacional de Investigaciones Científicas y Técnicas (CONICET) and Agencia de Promoción Científica y Tecnológica, Argentina, for their grants and the generous donation of Fundación Honorio Bigand.

\section{References}

Abel EL \& Moore C 1987 Effects of paternal alcohol consumption in mice. Alcoholism Clinical and Experimental Research 11 533-535. (https://doi. org/10.1111/j.1530-0277.1987.tb00168.x)
Anderson RA Jr, Willis BR, Oswald C \& Zaneveld LJ 1983 Ethanol-induced male infertility: impairment of spermatozoa. Journal of Pharmacology and Experimental Therapeutics 225 479-486.

Anderson RA, Berryman SH, Phillips JF, Feathergill KA, Zaneveld LJD \& Russel LD 1989 Biochemical and structural evidence for ethanolinduced impairment of testicular development: apparent lack of Leydig cell involvement. Toxicology and Applied Pharmacology 100 62-85. (https://doi.org/10.1016/0041-008X(89)90092-6)

Anifandis G, Bounartzi T, Messini Cl, Dafopoulos K, Sotiriou S \& Messinis IE 2014 The impact of cigarette smoking and alcohol consumption on sperm parameters and sperm DNA fragmentation (SDF) measured by Halosperm( ( $)$. Archives of Gynecology and Obstetrics 290 777-782. (https://doi.org/10.1007/s00404-014-3281-x)

Auger J, Eustache F, Andersen AG, Irvine DS, Jørgensen N, Skakkebaek NE, Suominen J, Toppari J, Vierula M \& Jouannet P 2001 Sperm morphological defects related to environment, lifestyle and medical history of 1001 male partners of pregnant women from four European cities. Human Reproduction 16 2710-2717. (https://doi.org/10.1093/ humrep/16.12.2710)

Bailey JL 2010 Factors regulating sperm capacitation. System in Biology Reproductive and Medicine 56 334-348. (https://doi.org/10.3109/193 96368.2010.512377)

Bonthius DJ, Tzouras G, Karacay B, Mahoney J, Hutton A, McKim R \& Pantazis NJ 2002 Deficiency of neuronal nitric oxide synthase (nNOS) worsens alcohol-induced microencephaly and neuronal loss in developing mice. Developmental Brain Research 138 45-59. (https:// doi.org/10.1016/S0165-3806(02)00458-3)

Canteros MG, Rettori V, Franchi A, Genaro A, Cebral E, Faletti A, Gimeno M \& McCann SM 1995 Ethanol inhibits luteinizing hormonereleasing hormone (LHRH) secretion by blocking the response of $\mathrm{LHRH}$ neuronal terminals to nitric oxide. PNAS 92 3416-3420. (https://doi. org/10.1073/pnas.92.8.3416)

Cebral E, Lasserre A, Rettori V \& De Gimeno MA 1997 Impaired mouse fertilization by low chronic alcohol treatment. Alcohol and Alcoholism 32 563-572.

Cebral E, Lasserre A, Faletti A \& Gimeno MA 1998a Response to ovulatory induction following moderate chronic ethanol administration in mice. Medical Science Research 26 29-31.

Cebral E, Lasserre A, Motta A \& Gimeno MAF 1998b Mouse oocyte quality and prostaglandin synthesis by cumulus oocyte complex after moderate chronic ethanol intake. Prostaglandins Leukotrienes and Essential Fatty Acids 58 381-387. (https://doi.org/10.1016/S0952-3278(98)90075-8)

Cebral E, Abrevaya XC \& Mudry MD 2011 Male and female reproductive toxicity induced by sub-chronic ethanol exposure in CF-1 mice. Cell Biology and Toxicology 27 237-248. (https://doi.org/10.1007/s10565-011-9185-7)

Cicero T \& Badger T 1977 Effects of alcohol on the hypothalamic-pituitarygonadal axis in the male rat. Journal of Pharmacology and Experimental Therapeutics 201 427-433.

Coll TA, Chaufan G, Pérez-Tito LG, Ventureira MR, Ríos de Molina MDC \& Cebral E 2018 Cellular and molecular oxidative stress-related effects in uterine myometrial and trophoblast-decidual tissues after perigestational alcohol intake up to early mouse organogenesis. Molecular and Cellular Biochemistry 440 89-104. (https://doi.org/10.1007/s11010-017-3158-y)

Condorelli RA, Calogero AE, Vicari E \& La Vignera S 2015 Chronic consumption of alcohol and sperm parameters: our experience and the main evidences. Andrologia 47 368-379. (https://doi.org/10.1111/ and.12284)

Creasy DM \& Chapin RE 2014 Testicular and epididymal toxicity: pathogenesis and potential mechanisms of toxicity. Spermatogenesis 4 e1005511. (https://doi.org/10.1080/21565562.2014.1005511)

Christova Y, James PS \& Jones R 2004 Lipid diffusion in sperm plasma membranes exposed to peroxidative injury from oxygen free radicals. Molecular Reproduction and Development 68 365-372. (https://doi. org/10.1002/mrd.20084)

Dees WL, Skelley CW, Hiney JK \& Johnston CA 1990 Actions of ethanol on hypothalamic and pituitary hormones in prepubertal female rats. Alcohol 7 21-25. (https://doi.org/10.1016/0741-8329(90)90055-H)

De Grava Kempinas W \& Klinefelter GR 2014 Interpreting histopathology in the epididymis. Spermatogenesis 4 e979114. (https://doi.org/10.4161 /21565562.2014.979114)

de Jong AM, Menkveld R, Lens JW, Nienhuis SE \& Rhemrev JP 2014 Effect of alcohol intake and cigarette smoking on sperm parameters and pregnancy. Andrologia 46 112-117. (https://doi.org/10.1111/and.12054) 
Eid NA, Shibata MA, Ito Y, Kusakabe K, Hammad H \& Otsuki Y 2002 Involvement of Fas system and active caspases in apoptotic signalling in testicular germ cells of ethanol-treated rats. International Journal of Andrology 25 159-167. (https://doi.org/10.1046/j.13652605.2002.00341.x)

Evans JP 2012 Sperm-egg interaction. Annual Review of Physiology 74 477-502. (https://doi.org/10.1146/annurev-physiol-020911-153339)

Firns S, Cruzat VF, Keane KN, Joesbury KA, Lee AH, Newsholme P \& Yovich JL 2015 The effect of cigarette smoking, alcohol consumption and fruit and vegetable consumption on IVF outcomes: a review and presentation of original data. Reproductive Biology and Endocrinology 13 134. (https://doi.org/10.1186/s12958-015-0133-x)

Florman HM \& Ducibella T 2006 Fertilization in Mammals, 3rd ed. New York, NY: Elsevier Academic Press.

Fujii J \& Imai H 2014 Redox reactions in mammalian spermatogenesis and the potential targets of reactive oxygen species under oxidative stress. Spermatogenesis 4 e979108. (https://doi.org/10.4161/21565562.2014. 979108)

Fraser LR \& Drury LM 1975 The relationship between sperm concentration and fertilization in vitro of mouse eggs. Biology of Reproduction 13 513-518. (https://doi.org/10.1095/biolreprod13.5.513)

Gaur D, Talekar M \& Pathak VP 2010 Alcohol intake and cigarette smoking: impact of two major lifestyle factors on male fertility. Indian Journal of Pathology and Microbiology 53 35-40. (https://doi.org/10.4103/03774929.59180)

Hansen ML, Thulstrup AM, Bonde JP, Olsen J, Håkonsen LB \& RamlauHansen CH 2012 Does last week's alcohol intake affect semen quality or reproductive hormones? A cross-sectional study among healthy young Danish men. Reproductive Toxicology 34 457-462. (https://doi. org/10.1016/j.reprotox.2012.06.004)

Herrero MB, Cebral E, Franchi A, Motta A \& Gimeno MF 1998 Progesterone enhances prostaglandin E2 production via interaction with nitric oxide in the mouse acrosome reaction. Biochemical and Biophysical Research Communications 252 324-328. (https://doi. org/10.1006/bbrc.1998.9638)

Jabbari S, Sadeghi MR, Akhondi MM, Ebrahimi Habibi A, Amirjanati N, Lakpour N, Asgharpour L \&Ardekani AM 2009 Tyrosine phosphorylation pattern in sperm proteins isolated from normospermic and teratospermic men. Journal of Reproduction and Infertility 10 185-191.

Jensen TK, Gottschau M, Madsen JO, Andersson AM, Lassen TH, Skakkebæk NE, Swan SH, Priskorn L, Juul A \& Jørgensen N 2014 Habitual alcohol consumption associated with reduced semen quality and changes in reproductive hormones; a cross-sectional study among 1221 young Danish men. BMJ Open 4 e005462. (https://doi. org/10.1136/bmjopen-2014-005462)

Joo KJ, Kwon YW, Myung SC \& Kim TH 2012 The effects of smoking and alcohol intake on sperm quality: light and transmission electron microscopy findings. Journal of International Medical Research 40 2327-2335. (https://doi.org/10.1177/030006051204000631)

Laemmli UK 1970 Cleavage of structural proteins during the assembly of the head of bacteriophage T4. Nature 227 680-685. (https://doi. org/10.1038/227680a0)

Lee HY, Naseer MI, Lee SY \& Kim MO 2010 Time-dependent effect of ethanol on $\mathrm{GnRH}$ and $\mathrm{GnRH}$ receptor mRNA expression in hypothalamus and testis of adult and pubertal rats. Neuroscience Letters 471 25-29. (https://doi.org/10.1016/j.neulet.2010.01.002)

Lewis-Jones I, Aziz N, Seshadri S, Douglas A \& Howard P 2003 Sperm chromosomal abnormalities are linked to sperm morphologic deformities. Fertility and Sterilility 79 212-215. (https://doi.org/10.1016/ S0015-0282(02)04411-4)

Martini AC, Molina RI, Estofán D, Senestrari D, Fiol de Cuneo M \& Ruiz RD 2004 Effects of alcohol and cigarette consumption on human seminal quality. Fertility and Sterility 82 374-377. (https://doi.org/10.1016/j. fertnstert.2004.03.022)

Mittleman G, Van Brunt CL \& Matthews DB 2003 Schedule-induced ethanol self-administration in DBA/2J and C57BL/6J mice. A/coholism Clinical and Experimental Research 97 918-925. (https://doi. org/10.1111/j.1530-0277.2003.tb04416.x)

Morton RA, Diaz MR, Topper LA \& Valenzuela CF 2014 Construction of vapor chambers used to expose mice to alcohol during the equivalent of all three trimesters of human development. Journal of Visualized Experiments 131-9. (https://doi.org/10.3791/51839)
Muthusami K \& Chinnaswamy P 2005 Effect of chronic alcoholism on male fertility hormones and semen quality. Fertility and Sterility 84 919-924. (https://doi.org/10.1016/j.fertnstert.2005.04.025)

Nicolau P, Miralpeix E, Solà I, Carreras R \& Checa MA 2014 Alcohol consumption and in vitro fertilization: a review of the literature. Gynecological Endocrinology 30 759-763. (https://doi.org/10.3109/09 513590.2014.938623)

Ogilvie K, Lee S \& Rivier C 1997 Effect of three different modes of alcohol administration on the activity of the rat hypothalamic-pituitary-adrenal axis. Alcoholism Clinical and Experimental Research 21 467-476. (https://doi.org/10.1111/j.1530-0277.1997.tb03792.x)

Pajarinen J, Karhunen PJ, Savolainen V, Lalu K, Penttilä A \& Laippala P 1996 Moderate alcohol consumption and disorders of human spermatogenesis. Alcoholism Clinical and Experimental Research 20 332-337. (https://doi.org/10.1111/j.1530-0277.1996.tb01648.x)

Rahimipour M, Talebi AR, Anvari M, Sarcheshmeh AA \& Omidi M 2013 Effects of different doses of ethanol on sperm parameters, chromatin structure and apoptosis in adult mice. European Journal of Obstetrics and Gynecology and Reproductive Biology 170 423-428. (https://doi. org/10.1016/j.ejogrb.2013.06.038)

Rhodes JS, Best K, Belknap JK, Finn DA \& Crabbe JC 2005 Evaluation of a simple model of ethanol drinking to intoxication in $\mathrm{C} 57 \mathrm{BL} / 6$ J mice. Physiology and Behavior 84 53-63. (https://doi.org/10.1016/j. physbeh.2004.10.007)

Rossi BV, Berry KF, Hornstein MD, Cramer DW, Ehrlich S \& Missmer SA 2011 Effect of alcohol consumption on in vitro fertilization. Obstetrics and Gynecology 117 136-142. (https://doi.org/10.1097/ AOG.0b013e31820090e1)

Salonen I, Pakarinen P \& Huhtaniemi I 1992 Effect of chronic ethanol diet on expression of gonadotropin genes in the male rat. Journal of Pharmacology and Experimental Therapeutics 260 463-467.

Sanchez MC, Sedo CA, Julianelli VL, Romanato M, Calvo L, Calvo JC \& Fontana VA 2013 Dermatan sulfate synergizes with heparin in murine sperm chromatin decondensation. Systems Biology in Reproductive Medicine 59 82-90. (https://doi.org/10.3109/19396368.2012.756952)

Shayakhmetova GM, Bondarenko LB, Matvienko AV \& Kovalenko VM 2014 Chronic alcoholism-mediated metabolic disorders in albino rat testes. Interdisciplinary Toxicology 7 165-72. (https://doi.org/10.2478/ intox-2014-0023)

Shayakhmetova GM, Bondarenko LB, Kovalenko VM \& Ruschak VV 2013 CYP2E1 testis expression and alcoholmediated changes of rat spermatogenesis indices and type I collagen. Archives of Industrial Hygiene and Toxicology 64 51-60. (https://doi.org/10.2478/100041254-64-2013-2313)

Shirai T \& Ikemoto I 1992 Mechanism of alcoholic testicular damage. Nippon Hinyokika Gakkai Zasshi 83 305-314.

Sliwowska JH, Comeau WL, Bodnar TS, Ellis L \& Weinberg J 2016 Prenatal alcohol exposure and pair feeding differentially impact puberty and reproductive development in female rats: role of the kisspeptin system. Alcoholism: Clinical and Experimental Research 40 2368-2376. (https:// doi.org/10.1111/acer.13233)

Stutz G, Zamudio J, Santillán ME, Vincenti L, de Cuneo MF \& Ruiz RD 2004 The effect of alcohol, tobacco, and aspirin consumption on seminal quality among healthy young men. Archives of Environmental Health 59 548-552. (https://doi.org/10.1080/00039890409603432)

Talebi AR, Sarcheshmeh AA, Khalili MA \& Tabibnejad N 2011 Effects of ethanol consumption on chromatin condensation and DNA integrity of epididymal spermatozoa in rat. Alcohol 45 403-409. (https://doi. org/10.1016/j.alcohol.2010.10.005)

Towbin H, Staehelin T \& Gordon J 1979 Electrophoretic transfer of proteins from polyacrylamide gels to nitrocellulose sheets: procedure and some applications. PNAS $\mathbf{7 6}$ 4350-4354. (https://doi.org/10.1073/ pnas.76.9.4350)

Välimäki M, Tuominen JA, Huhtaniemi I \& Ylikahri R 1990 The pulsatile secretion of gonadotropins and growth hormone, and the biological activity of luteinizing hormone in men acutely intoxicated with ethanol. Alcoholism: Clinical and Experimental Research 14 928-931.

Van Heertum K \& Rossi B 2017 Alcohol and fertility: how much is too much? Fertility Research and Practice 3 10. (https://doi.org/10.1186/ s40738-017-0037-x)

Van Thiel DH 1990 Disorders of the hypothalamic-pituitary-gonadal and thyroidal axes in patients with liver disease. In Hepatology. A Textbook 
of Liver Disease, 2nd ed., pp 513-529. Eds. D Zakim \& TD Boyer. Philadelphia: Saunders.

Visconti PE, Bailey JL, Moore GD, Pan D, Olds-Clarke P \& Kopf GS 1995 Capacitation of mouse spermatozoa I. Correlation between the capacitation state and protein tyrosine phosphorylation. Development 121 1129-1137.

Visconti PE, Krapf D, de la Vega-Beltrán JL, Acevedo JJ \& Darszon A 2011 Ion channels, phosphorylation and mammalian sperm capacitation. Asian Journal of Andrology 13 395-405. (https://doi.org/10.1038/ aja.2010.69)

Wdowiak A, Sulima M, Sadowska M, Grzegorz B \& Bojar I 2014 Alcohol consumption and quality of embryos obtained in programmes of in vitro fertilization. Annals of Agricultural and Environmental Medicine 21 450-453. (https://doi.org/10.5604/1232-1966.1108623)

Wieczorek L, Fish EW, O'Leary-Moore SK, Parnell SE \& Sulik KK 2015 Hypothalamic-pituitary-adrenal axis and behavioral dysfunction following early binge-like prenatal alcohol exposure in mice. Alcohol 49 207-217. (https://doi.org/10.1016/j.alcohol.2015.01.005)

Willis BR, Anderson RA, Oswald C \& Zaneveld LJ 1983 Ethanol-induced male reproductive tract pathology as a function of ethanol dose and duration of exposure. Journal Pharmacology Experimental Research 225 470-478.

Zhang CR \& Chong S 2016 Gene expression in the mouse brain following early pregnancy exposure to ethanol. Genomics Data 10 107-108. (https://doi.org/10.1016/j.gdata.2016.10.007)

Zhang X, Sliwowska JH \& Weinberg J 2005 Prenatal alcohol exposure and fetal programming: effects on neuroendocrine and immune function. Experimental Biology and Medicine 230 376-388. (https://doi. org/10.1177/15353702-0323006-05)

Received 14 August 2017

First decision 29 September 2017

Revised manuscript received 28 March 2018 Accepted 6 April 2018 